\title{
BUDAYA POPULER GAME POKEMON GO SEBAGAI SOFT DIPLOMACY JEPANG
}

\author{
Chadijah Isfariani Iqbal \\ Universitas Hasanuddin \\ Email: chisfariani@gmail.com
}

\begin{abstract}
Pokemon Go is a smartphone game that blends the real and digital worlds, tasking players with exploring their neighborhoods to find creatures and treasure for in-game use. This research describes the ways Japan uses its soft power in international coorporation relations, particulary through Pokemon Go's game. Based on Joseph S. Nye, Jr, the soft power defined as the ability of country to achieve its goal using cultural attraction rather than coercion and violence. After the World War II, Japan has tried to change its image as war crime through popular culture, such as anime, manga and cosplay. According to Nye, Japan has more potential resources in soft power compared to the other countries. This research is focus on Popular Culture of Pokemon Go's Game as Japan's Soft Diplomacy. Pokemon Go is one of Japan's cultural diplomacy activities and the other countries uses popular culture to strengthen the positive image of Japan in the international world. The development of popular culture as a soft power and soft diplomacy also a diplomacy tool of development that can be used by Japan in conducting foreign policy in relation to international cooperation.
\end{abstract}

Keywords : Game, Pokemon Go, Popular Culture Soft Diplomacy, Soft Power.

\section{PENDAHULUAN}

Seiring dengan perkembangan zaman, dalam usaha mengejar kepentingan nasionalnya Negara-negara tidak hanya menekankan pada kekuatan militer atau ekonomi saja melainkan juga pada kebudayaannya. Joseph, S. Nye, Jr. (2004) menyatakan bahwa sumber kekuatan sebuah Negara pasca Perang Dunia II tidak hanya bergantung pada kekuatan militer saja melainkan pada sumber lain seperti budaya dan kebiasaan yang disebut Soft Power. Joseph S. Nye melihat Soft Power Jepang bukan hanya berasal dari budaya tradisional Jepang seperti Zen, Karate, tetapi juga berasal dari manga, anime, dan elemen budaya populer lainnya (Joseph S. Nye, 2004).

Sejak tahun 1990an Jepang telah dikenal sebagai Negara maju yang tetap mempertahankan dan memelihara budayanya sehingga mendapatkan perhatian besar di dunia internasional. Selain memelihara budaya tradisional, Jepang juga mengembangkan budaya populernya. Budaya populer Jepang atau yang sering disebut Japanese Popular Culture. tersebut telah berhasil menarik perhatian masyarakat Internasional. Beberapa contoh produk budaya populer Jepang adalah manga/komik, anime/animasi, game/permai nan, j-music/music jepang, dan dorama (drama televisi). Melalui berbagai produk budaya populernya, Jepang secara tidak langsung memperkenalkan nilai-nilai serta budaya tradisional Jepang.

Pengaruh budaya populer Jepang di berbagai belahan dunia sudah tidak dapat diragukan lagi. Budaya populer Jepang menjadi semakin mendunia dan sangat mudah diakses dalam berbagai bahasa. Penjualan-penjualan produk budaya populer Jepang melesat dalam angka yang cukup 
Izumi, Volume 5, No 2, 2016

e-ISSN: 2502-3535, p-ISSN: 2338-249X

Tersedia online di http://ejournal.undip.ac.id/index.php/izumi

signifikan, seperti halnya penjualan $\mathrm{CD}$ yang bahkan angka preorder Internasional nya pun dapat menembus angka satu juta kopi. Klubklub pengkaji kebudayaan Jepang pun semakin banyak dan tidak hanya itu, bahkan banyak klub yang mengkajinya secara spesifik. Oleh karena itu, menjadi sangat penting untuk melihat bagaimana pemerintahan Jepang memanfaatkan pop culture sebagai sarana diplomasi efektif untuk menyebarkan pengaruhnya. (Rininta, 2015)

Seperti halnya dengan Doraemon yang sudah sangat di kenal sebagai Duta Budaya Animasi Jepang. Pokemon juga adalah salah satu dari ikon animasi Jepang yang juga menjadi ikon budaya populer Jepang. Pokemon sendiri menurut Yomota (2006) adalah ikon pendobrak monster mainstream yang berukuran besar seperti dinosaurus dalam film Jurassic Park. Di saat Amerika menciptakan berbagai jenis karakter binatang purba berukuran raksasa yang sudah punah yang dihidupkan kembali di dalam sebuah taman hiburan, Jepang malah menciptakan monster dinosaurus yang berukuran kecil. Saking kecilnya, monstermoster tersebut bisa dimasukkan ke dalam kantong hingga dinamakan sebagai Pokemon. Adanya demam Pokemon Go menjalar dimana-mana yang merupakan game yang sangat populer di berbagai Negara baru-baru ini, menunjukan bahwa pemerintah Jepang telah memanfaatkan ikon animasi Pokemon yang juga menjadi ikon budaya populer Jepang berupa game Pokemon Go sebagai soft diplomacy-nya dalam menjalin hubungan dengan dunia internasional. Budaya populer Jepang yang dikembangkan sebagai soft power negara tersebut telah memainkan peranan yang cukup penting dalam diplomasi Jepang. Penelitian ini bertujuan untuk mengetahui secara mendalam serta menyampaikan mengenai budaya popular Pokemon Go yang telah di manfaatkan oleh Jepang soft diplomacy dalam menjalin hubungan kerjasamanya dengan dunia internasional.

\section{Metode Penelitian}

Metode penelitian yang digunakan adalah metode kualitatif yang menggunakan interpretasi logis dengan mengumpulkan fakta-fakta yang ada. Metode penelitian kualitatif menghasilkan data dengan cara terlebih dahulu mengolah data yang bersifat deskriptif. Sumber data yang digunakan dalam penelitian ini adalah data sekunder yang diperoleh dari mengumpulkan data-data yang diperlukan dalam penelitian atau mengumpulkan referensi dan literatur terkait dengan penelitian ini seperti laporan penelitian, jurnal serta buku referensi dan data-data pendukung lainnya di berbagai website yang memiliki keterkaitan dengan penelitian ini.

\section{BUDAYA POPULER JEPANG}

Menurut Craig (2000:4), budaya populer Jepang dapat dikatakan unsur-unsur budaya yang mengacu pada modern Jepang. Beberapa elemen dari budaya populer Jepang terkenal di seluruh dunia mencakup anime, game, cosplay, gaya busana harajuku-kei, manga, kesenian Jepang, fashion Jepang, dan sebagainya. Di seluruh dunia baik anak-anak, remaja, dan dewasa telah terpesona dengan budaya populer Jepang ini. Budaya populer Jepang tidak hanya berkembang hanya di Negaranya tetapi juga telah menarik simpati dari luar negeri yang memberikan pujian terhadap dampak budaya Jepang baru di dunia. Budaya populer Jepang sekarang ada dimana-mana, hangat diperbincangkan dan semakin berpengaruh ke Negara lain. Jepang memberikan kontribusi bukan hanya untuk kehidupan materi saja tetapi untuk kehidupan kebudayaan juga.

Di Jepang, budaya populer justru memang sengaja disebarkan ke luar negeri sebagai salah satu strategi kemajuan Jepang, terbukti dalam pernyataan Nobuyuki (2007: 107) sebagai berikut:

「日本には能や歌舞伎のような伝統

的な文化から、秋葉原のオタク文 化

に象徵されるゲームやアニメといっ

た新しいコンテンツ産業まで、世界

に輸出できる文化がたくさんありま

す。そられを積極的に支援していく 
Izumi, Volume 5, No 1, 2016

e-ISSN: 2502-3535, p-ISSN: 2338-249X

Tersedia online di http://ejournal.undip.ac.id/index.php/izumi

のです。塩野七生さんによれば、帝 政ロ一マ時代から、文明社 会はまず 政治的成熟し、次いで経済的に成熟 し、最後には必ず文的にも成熟する そうです。これからの日本は誇りを もって、成熟した『文化国家』とし てやっていくべきです。」

Penjelasan di atas dimaknai bahwa, di Jepang terdapat banyak budaya yang dapat diekspor ke seluruh dunia, mulai dari budaya tradisional seperti Noh dan Kabuki, sampai materi budaya baru seperti game dan anime yang disimbolkan sebagai budaya otaku dari Akihabara. Hal - hal tersebut secara aktif membantu penyebaran budaya. Menurut Shiono Nanami, sejak zaman Imperial di Roma dahulu, masyarakat yang beradab awalnya matang secara politik, kemudian secara ekonomi, dan terakhir secara literasi. Jepang mulai saat ini harus bangga menjalankan perannya sebagai "Negeri budaya". Dari pernyataan tersebut dapat dilihat bahwa budaya Jepang sekarang banyak dikenal oleh negara lain tanpa terkecuali Indonesia.

\section{KONSEP SOFT POWER DAN SOFT DIPLOMACY}

\section{a. Soft Power}

Analisis pada penelitian ini akan didasarkan pada teori Soft Power yang ditawarkan Joseph Nye dalam bukunya, Soft Power (2004), dan cara kerja Soft Power yang ditawarkan oleh Alexander Vuving dalam tulisannya yang berjudul "How Soft Power Works" (2009).

Nye menyebutkan bahwa memiliki banyak sumber Soft Power tidak dapat menjamin naiknya pamor suatu Negara. Hal ini karena Soft Power yang dihasilkan oleh sumber-sumber tersebut tidak bisa langsung sampai ke masyarakat yang menjadi sasaran (recipient). Nye telah menyadari ini, tetapi tidak menyebutkan cara Soft Power sampai ke recipient. Oleh karena itu, Alexander Vuving melengkapinya dengan menawarkan konsep 'Soft Power Currencies', dalam tulisannya "How Soft Power Works" (2009). Soft power currencies adalah cara Soft Power untuk sampai ke recipient (Vuving, 2009). Soft power memerlukan soft power currencies seperti air yang memerlukan pipa untuk sampai ke rumah-rumah.

Vuving mengidentifikasikan ada tiga soft power currencies: beauty, brilliance, dan benignity. Beauty adalah resonansi dari norma dan tujuan yang dimiliki bersama, brilliance adalah daya tarik yang dihasilkan dari kemampuan dan kesuksesan, dan benignity adalah kebaikan yang terlihat dari perilaku dan sikap (Vuving, 2009).

Konsep soft power currencies memiliki relevansi dalam penelitian ini karena game Pokemon Go merepresentasikan ketiga elemen dari soft power currencies khususnya elemen brilliance sebab berbagai produk budaya populer Jepang (manga, anime dan game) mampu menarik perhatian dan rasa kagum anak-anak muda dari berbagai Negara kepada Jepang. Hal ini kemudian mengarah pada ketertarikan kepada game Pokemon Go. Selain dari elemen brilliance, terdapat juga elemen beauty dalam game Pokemon Go ini. Elemen beauty yang ingin ditunjukkan oleh Jepang dalam Pokemon Go ini adalah nilai-nilai kebebasan. Pengaplikasian dari nilai kebebasan ini tampak dari kebebasan mengunduh secara gratis game Pokemon Go dan kebebasan dalam memainkan permainan ini dalam ponsel pintar pemainnya serta kebebasan mengekspresikan permainan tersebut sesuka hati mereka. Berdasarkan pada elemen benignity, Pokemon Go mendorong pemain melakukan eksplorasi di alam nyata dan berinteraksi dengan para pemain lain.

Dunia game, khususnya di SMARTPHONE, para pemain berlombalomba berlari keluar rumah, bepergian ke lokasi tertentu, dan menangkap monster lucu dan imut, bernama Pokemon. Dunia saat ini sedang keranjingan sebuah game baru bernama "POKEMON GO". POKEMON GO merupakan game berbasis AUGMENTED-REALITY yang dikembangkan oleh Pokemon Company 
Izumi, Volume 5, No 2, 2016

e-ISSN: 2502-3535, p-ISSN: 2338-249X

Tersedia online di http://ejournal.undip.ac.id/index.php/izumi

bekerja sama dengan Nintendo dan Niantic. (Kompas.com, 2016)

\section{b. Soft Diplomacy}

Tidak dapat dipungkiri bahwa soft power memiliki peran dan posisi yang penting dalam kehidupan nyata, bahkan sering dianggap bahwa nilai power ini jauh lebih tinggi daripada aset ekonomi dan militer yang dimiliki suatu Negara. Soft power bersumber dari nilai-nilai dan kebudayaan yang ada di Negara itu sendiri dan sebagai bentuk penyalurannya, soft power disampaikan melalui diplomasi publik, atau dikenal sebagai soft diplomacy. Diplomasi publik bentuk ini merupakan alat yang digunakan pemerintah untuk memobilisasi sumber-sumber soft power tersebut yang lebih ditujukan untuk menarik perhatian masyarakat umum suatu Negara daripada pemerintah Negaranya. Dalam konteks ini, soft diplomacy berfungsi untuk membentuk opini publik dan pencitraan. Dengan kata lain, diplomasi publik tak ubahnya sebagai kampanye public relations yang menjual image positif suatu Negara, yang dapat menciptakan sebuah hubungan jangka panjang dan lingkungan yang sesuai dengan arah kebijakan dan kepentingan nasional sebuah pemerintah.

Dalam konteks soft diplomacy, pengertian yang paling dekat maknanya adalah diplomasi kebudayaan. Posisi kebudayaan tidak dapat dipandang sebelah mata, karena ia juga memiliki pengaruh yang besar dalam sebuah diplomasi. Dr. Jessica Gienow-Hecht, editor dari manuscript Searching for a Cultural Diplomacy, menyebutkan bahwa cultural diplomacy memiliki dimensi arti yang terkait dengan manipulasi politik dan sub-ordinasi, serta sebagai the backseat of diplomatic interactions atau dengan kata lain beyond propaganda. Sehingga, soft diplomacy ini semakin memiliki pengaruh yang penting dalam politik internasional.

Awal pelaksanaan soft diplomacy ini dimulai oleh Jepang dengan menggunakan budaya sebagai sarana mempengaruhi Negara lain untuk meningkatkan citra Jepang.
Komik Jepang yang dikenal dengan nama manga, film-film kartun seperti doraemon, atau animasi (populer dengan sebutan anime) seperti Pokemon menghasilkan apresiasi luar biasa terhadap Jepang.

Melalui soft diplomacy, Negara berusaha sedapat mungkin untuk memikat Negara lain sekaligus masyarakat yang ada di dalamnya dengan kebudayaan yang dimiliki dan nilai-nilai yang dianutnya. Oleh karena itu soft diplomacy yang berwujud budaya lebih menghasilkan diplomasi yang kuat, seperti apa yang telah diutarakan oleh Susanto Pudjomartono seorang mantan Dubes Indonesia untuk Rusia bahwa soft diplomacy ini diartikan sebagai pertukaran gagasan, informasi, seni dan aspek-aspek kebudayaan lain antara Negara dan bangsa, dengan harapan bisa menciptakan pengertian bersama. (Pudjomartono, 2011)

\section{GAME POKEMON GO}

Game merupakan suatu sistem yang memiliki aturan-aturan tertentu dimana pemain akan terlibat di dalam suatu permasalahan sehingga dapat menghasilkan suatu hasil yang dapat diukur yaitu menang atau kalah (Salen \& Zimmerman, 2003). Game online adalah jenis permainan komputer yang memanfaatkan jaringan komputer (LAN atau internet) sebagai medianya. Menurut Andrew Rollings dan Ernest Adams (2006), game online lebih tepatnya disebut sebagai sebuah teknologi dibandingkan sebagai sebuah genre atau jenis permainan, sebuah mekanisme untuk menghubungkan pemain bersama dibandingkan pola tertentu dalam sebuah permainan.

Permainan (game) maupun game online banyak disukai oleh semua kalangan baik anak-anak, remaja maupun dewasa. Game itu sendiri tidak akan pernah habis dimakan waktu, selalu ada muncul teknologi untuk memperbaruhi trend game itu sendiri, baik jenis game maupun perbaharuan game. Menurut Bartle (1996), merumuskan empat tipe pemain seperti achievers, yakni mereka yang bermain untuk mencapai sasaransasaran tertentu dan meningkatkan 
Izumi, Volume 5, No 1, 2016

e-ISSN: 2502-3535, p-ISSN: 2338-249X

Tersedia online di http://ejournal.undip.ac.id/index.php/izumi

kemampuan mereka didalam game tersebut; explorers, yakni mereka yang suka menjelajah dan menyelidiki dunia permainan; socializers, yakni mereka yang suka bersosialisasi dan berhubungan dengan para pemain lain dan tidak selalu dalam konteks permainan; griefs, yakni mereka yang suka mengganggu atau menyakiti para pemain lain.

Pokemon Go adalah game augmented reality (realitas tertambah) di ponsel pintar. Ini menggunakan GPS (Sistem Pemosisi Global). Cara bermain dengan berjalan-jalan di dunia nyata menangkap monster virtual yang menggemaskan seperti Pikachu dan Jigglypuff di tempat-tempat dekat lokasi ponsel Anda dan melatih mereka untuk bertanding. Monster-monster ini pertama kali populer pada tahun 90 -an ketika Nintendo Game Boy muncul. Kartu-kartu permainan untuk ditukar sangat laku di taman bermain di sekolah-sekolah jauh sebelum Minecraft dan bahkan sebelum Tamagotchi, namun setelah yoyo dan kelereng.

\section{GAME POKEMON GO SEBAGAI SOFT POWER JEPANG}

Salah satu sumber Soft Power menurut Nye adalah kemampuan menarik perhatian dari budaya yang dimiliki suatu Negara, seperti budaya populer. Jepang yang memiliki kemampuan untuk mengembangkan budaya populer game dapat menjadikan budaya tersebut sebagai soft power-nya, seperti pada game Pokemon GO. Game Pokemon Go yang baru saja dikeluarkan di bulan Juli 2016 lalu, sudah menampakkan sesuatu yang luar biasa baru terkenal ke berbagai negara. Hal ini bahkan membuat para pengguna smartphone atau ponsel pintar lebih menghabiskan waktu mereka untuk mengejar dan mencari Pokemon.

POKEMON GO merupakan game berbasis AUGMENTED-REALITY yang telah dikembangkan oleh Pokemon Company bekerja sama dengan Nintendo dan Niantic. Nama perusahaan Niantic ini sudah banyak dikenal di kalangan GAMER SMARTPHONE. Lantaran perusahaan spin off Google ini merupakan sisi lain di balik game populer INGRESS, yang juga berbasiskan AUGMENTED-REALITY.

Dikutip dari tulisan yang berasal dari majalah online Tekno.kompas.com bahwa Nama John Hanke melonjak bersamaan dengan hadirnya Pokemon Go karena perusahaan yang dibangunnya "Niantic" yaitu satu dari tiga perusahaan yang ikut serta dalam mengembangkan game tersebut. Niantic memiliki bakat dalam teknologi geospasial serta GPS, yang kemudian diterapkan dalam game berbasis augmented reality.

Game pokemon Go juga dapat menyampaikan pesan yang ingin disampaikan melalui John Hanke kepada Negara lain seperti bermain secara aktif, hubungan persahabatan yang ingin dijalin oleh sesama gamer, sampai kepada pentingnya bersosialisasi dengan lingkungan sekitar.

\subsection{Fenomena Game Pokemon GO}

Pokemon Go, aplikasi permainan yang kini tengah digandrungi di dunia. Diciptakan pertama kali oleh Satoshi Tajiri pada 1995, awalnya game ini adalah seri permainan video yang identik dengan Game Boy dan Nintendo. Namun kini dengan menggunakan GPS, para pemburu monster dapat memburunya secara virtual di dunia nyata, seperti Pikachu, Jigglypuff, dan makhluk lainnya di tempat-tempat yang dekat dengan lokasi ponsel pintar.

Sebelum Pokemon Go hadir, Niantic sebetulnya sudah dikenal sebagai pengembang game Ingress yang merupakan game berbasis perangkat mobile yang menantang para gamer untuk mengeksplorasi dunia dan menguasai tempat-tempat tertentu sebagai kawasan miliknya. Ingress memanfaatkan teknologi augmented reality dan juga didasarkan pada pemetaan lokasi dengan GPS, yang mengajak pengguna mencari kekuatan virtual di tempat-tempat seperti museum, monumen, dan ruang terbuka publik.

Hanke menghendaki para gamer bersenang-senang secara aktif dalam memainkan Pokemon Go, dalam arti tidak 
Izumi, Volume 5, No 2, 2016

e-ISSN: 2502-3535, p-ISSN: 2338-249X

Tersedia online di http://ejournal.undip.ac.id/index.php/izumi

cuma duduk di toilet atau hanya bersantai di tempat tidur. Oleh karena itu ia ikut mengembangkan Pokemon Go yang idenya yaitu mampu menyeret kaki para gamer keluar rumah untuk memburu para monstermonster kemudian memasukkannya ke dalam bola Pocketball.

Hanke memiliki keinginan besar agar para pengguna Pokemon Go tetap bersosialisasi dengan lingkungan sekitar. Hal tersebut kelihatannya terwujud, terbukti dari gamer Pokemon Go rela pergi keluar rumah, berjalan kaki, berpetualang, hingga kenalan dengan orang baru.

Secara menyeluruh, POKEMON GO merupakan game gratis yang dikembangkan untuk pengguna Android dan $i O S$, aplikasi game yang membolehkan pemainnya untuk menangkap Pokemon yang tersembunyi di berbagai lokasi dunia nyata. Di dalam game itu sendiri, para pihak pengembang game menyiapkan beberapa item yang bisa dibeli dengan uang. Tujuan dari ITEM berbayar (IN APP PURCHASE), salah satunya adalah untuk mempercepat pengembangan Pokemon yang dimiliki pemain. Game Pokemon Go ini memiliki lokasi tersendiri di dunia nyata. Untuk mendapatkannya, pemain harus keluar rumah dan pergi ke lokasi secara spesifik.

Berkat pengalaman dan kerja kerasnya selama 20 tahun, Pokemon Go berhasil menjadi game fenomenal. Dari setiap perjalanan karir yang dilalui, John Hanke tidak tahu bakal apa seperti jadinya. Namun Hanke selalu fokus pada setiap level perjalanan karirnya. Kesuksesan Pokemon Go saat ini bukanlah hasil kerja semalam John Hanke. Melalui perjalanan karirnya selama 20 tahun, Hanke berhasil membuat Pokemon Go sukses seperti sekarang ini.

Hampir semua hal di dunia ini memiliki sisi baik dan buruk, termasuk sebuah GAME. Begitu juga dengan Pokemon Go buatan John Hanke dari Niantic Labs. GAME ini memang membuat seseorang aktif bergerak dan keluar ruangan. "Namun, saya kini sadar bahwa GAME ini punya dampak yang tidak sesuai dengan harapan," ujarnya saat konferensi Games
Beat 2016 di Rancho Palos Verdes, California, baru-baru ini. Para pemain Pokemon Go seolah kecanduan dengan SMARTPHONE-nya. Hampir setiap saat mereka memperhatikan layar telepon untuk melihat PokeStop terdekat atau keberadaan Pokemon di sekitar mereka. "Padahal, saya ingin mereka juga melihat lingkungan sekitar, bukan hanya terpaku kepada layar ponsel," ujar Hanke.

Hal ini dapat menjadi pesan dalam soft power Jepang dan Negara lainnya dalam menyampaikan pandangan para penciptanya terhadap teknologi. Jepang sebagai salah satu negara yang terdepan dalam bidang teknologi memiliki pandangan bahwa teknologi yang canggih haruslah diikuti dengan standar produksi yang tinggi sehingga dapat dimanfaatkan dengan baik dalam kehidupan manusia. Apabila digunakan dengan baik, maka teknologi yang diciptakan dapat membawa kebaikan bagi manusia, dan sebaliknya apabila dimanfaatkan untuk hal yang tidak seharusnya, maka teknologi dapat berakibat buruk pada manusia dan juga alam sekitar. Dengan unsur kebudayaan yang ada, teknologi menjadi lebih mudah diterima karena kebudayaan merupakan hal yang sangat dekat dengan kehidupan manusia sehari-hari.

\subsection{Praktik Soft diplomacy Jepang dan Dunia melalui Game Pokemon GO}

Tujuan sebenarnya dari soft diplomacy adalah untuk mempromosikan citra positif dalam rangka meningkatkan kemampuan untuk menarik perhatian Negara lain. Seperti halnya Jepang yang telah berusaha untuk meningkatkan posisinya dalam tatanan internasional seiring dengan perkembangan soft power di dunia internasional. Dengan demikian, era dimana sektor industri yang memimpin pertumbuhan ekonomi suatu negara juga menjadi sangat didukung dari sektor kebudayaan dan hal tersebut berhasil dilakukan oleh kolaborasi 2 orang hebat melalui keberhasilan game Pokemon Go. Dua orang tersebut yaitu "John Hanke dan Satoshi Tajiri”. kedua nama itu 
Izumi, Volume 5, No 1, 2016

e-ISSN: 2502-3535, p-ISSN: 2338-249X

Tersedia online di http://ejournal.undip.ac.id/index.php/izumi

adalah sosok berharga di balik game Pokemon Go.

Dipublikasikan dari beberapa sumber menceritakan bahwa Pokemon yang memiliki singkatan Pocket Monsters hadir pertama kali di konsol portabel Game Boy. Pada 1990, Satoshi Tajiri yang mendesain sebuah konsep permainan bernama Capsule Monsters untuk Nintendo. Menurut buku Pikachu's Global Adventure, konsep game Capsule Monsters memiliki latar belakang masa kecil Tajiri yang hobi mengoleksi serangga. Nama Capsule Monsters sendiri terinspirasi dari mesin permainan Jepang, Gashapon, yang identik dengan bentuk kapsul berisi mainan di dalamnya. Sayangnya, Tajiri menemui kesulitan untuk menggunakan nama Gashapon karena permasalahan hak cipta. Karena itu, ia mengganti namanya menjadi CapuMon. Kemudian, CapuMon menjadi Pocket Monsters.

Nintendo berkali-kali menolak game Pocket Monster yang dibuat oleh Satoshi Tajiri karena Nintendo belum bisa mengerti mengenai konsep dan potensi dari game tersebut. Pada akhirnya tanpa menyerah, Tajiri berhasil mencuri perhatian Shigeru Miyamoto, penemu Donkey Kong dan Super Mario. Setelah itu, barulah Nintendo melunak dan mengembangkan game Pokemon selama lima tahun atau dari 1990 1995. Akhirnya, game Pokemon pertama dirilis ke pasar pada awal 1996 bernama Pokemon Red dan Green. Ternyata, game itu terbukti sukses dan membuat pihak pengembang segera merilis versi terbarunya, Pokemon Blue. Setelah itu, Pokemon mulai melebarkan sayapnya ke alam dalam episode anime. Pokemon juga hadir dalam bentuk permainan lain seperti card game, puzzle, hingga casual game. Pokemon terus menjadikan franchise populer hingga sekarang.

John Hanke adalah CEO dan pendiri Niantic sejak 2015. Ia pernah menjadi salah satu karyawan Google yang berjasa mengembangkan aplikasi Google Earth dan Maps yang sangat kental dengan unsur pemetaan. "Salah satu kunci pengembangan game Pokemon Go adalah pemetaan," kata Hanke kepada Mashable. Sekitar lima tahun lalu, Niantic membuat game Ingress yang berbasis augmented reality. Melalui game itu, Niantic meminta para penggemar untuk mengajukan berbagai tempat dan bangunan di seluruh dunia yang bisa dijadikan "portal" atau daerah kekuasaan dalam dunia Ingress. Ternyata, portal-portal paling populer yang dikirimkan oleh para pemain Ingress adalah basis data dari lokasi-lokasi Pokestop dan Gym dalam game Pokemon Go. Niantic menerima 15 juta usulan portal pada Ingress dan hanya menyetujui 5 juta lokasi di seluruh dunia sebagai tempat Pokestop dan Gym.

"Tempat-tempat yang dipilih merupakan lokasi yang sering didatangi masyarakat. Biasanya, tempat-tempat tersebut berupa museum, situs sejarah, atau tempat dengan desain arsitektur unik," ujar Hanke. Dalam menentukan habitat Pokemon, Niantic memilih tempat berdasarkan karakteristik suatu daerah seperti sungai, kolam, kebun binatang, atau taman. Karakter Pokemon seperti Magikarp dan Squirtles akan muncul di suatu area yang terdapat sumber air di dekatnya. Ke depannya, Niantic berencana memperkenalkan atur baru di Pokemon Go, seperti mengembangkan Pokestop dan Gym sesuai selera pemilik atau penguasanya serta atur trading atau bertukar karakter antarpengguna. "Kami berpikir atur baru itu akan mendorong lebih banyak kerja sama, persaingan, maupun interaksi sosial di antara para pemain, khususnya mereka yang berada di dalam tim yang sama," pungkas Hanke.

Hasil dari kolaborasi kedua orang tersebut merupakan salah satu kegiatan diplomasi budaya Jepang dan Negara lain yang menggunakan budaya populer untuk memperkuat citra positif Jepang pada tingkat global. Pemanfaatan budaya populer seperti Pokemon GO sebagai Soft diplomacy bertujuan agar Jepang dapat membangun citra positifnya di dunia internasional yang diperlukan untuk dapat membangun kerja sama yang baik dengan Negara lain. Selain itu, melalui budaya populer yang digunakan sebagai soft diplomacy, Jepang dapat 
Izumi, Volume 5, No 2, 2016

e-ISSN: 2502-3535, p-ISSN: 2338-249X

Tersedia online di http://ejournal.undip.ac.id/index.php/izumi

memberikan pemahaman yang lebih baik mengenai masyarakat, kebudayaan dan Negaranya kepada masyarakat internasional, yang dapat menghindari kesalah pahaman terhadap Jepang. Pengembangan budaya populer sebagai soft power dan sof diplomacy juga merupakan pengembangan dari alat diplomasi yang dapat digunakan Jepang dalam menjalankan politik luar negerinya dalam hubungan kerjasama internasionalnya.

\section{KESIMPULAN}

Salah satu sumber soft power menurut Nye adalah kemampuan menarik perhatian dari budaya yang dimiliki suatu Negara, seperti budaya populer. Jepang yang memiliki kemampuan untuk mengembangkan budaya populer game dapat menjadikan budaya tersebut sebagai soft powernya, seperti pada game Pokemon GO. Game Pokemon Go yang baru saja dikeluarkan di bulan Juli 2016 lalu, sudah menampakkan sesuatu yang luar biasa baru terkenal ke berbagai Negara. Hal ini bahkan membuat para pengguna smartphone atau ponsel pintar lebih menghabiskan waktu mereka untuk mengejar dan mencari Pokemon.

Game Pokemon Go merupakan salah satu kegiatan diplomasi budaya Jepang dan Negara lain yang menggunakan budaya populer untuk memperkuat citra positif Jepang pada tingkat global. Pemanfaatan budaya populer seperti Pokemon GO sebagai Soft diplomacy bertujuan agar Jepang dapat membangun citra positifnya di dunia internasional yang diperlukan untuk dapat membangun kerja sama yang baik dengan Negara lain. Selain itu, melalui budaya populer yang digunakan sebagai soft diplomacy, Jepang dapat memberikan pemahaman yang lebih baik mengenai masyarakat, kebudayaan dan Negaranya kepada masyarakat internasional, yang dapat menghindari kesalah pahaman terhadap Jepang. Pengembangan budaya populer sebagai soft power dan soft diplomacy juga merupakan pengembangan dari alat diplomasi yang dapat digunakan Jepang dalam menjalankan politik luar negerinya dalam hubungan kerjasama internasionalnya.

\section{DAFTAR PUSTAKA}

Bartle, R. A. 1996. Hearts, clubs, diamonds and spades: player who suits muds. Colchester Essex: MUSE Ltd.

Rininta, Chaula. 2015. Pop Culture: Revitalisasi Pengaruh Internasional Jepang. http://the-dailyjapan.com/popculture-revitalisasi-pengaruhinternasional-jepang

Craig, Timothy J., ed. 2000. Japan Pop! Inside The World of Japanese Popular Culture. New York: M. E. Sharpe, Inc.

Hadi, Syamsul, Ph.D. 2009 Checkbook Diplomacy Jepang dalam Hubungan dengan ASEAN: Relevansi dan Tantangan bagi Indonesia (Manuscript)
Inuhiko, Yomota. 2006. "Kawaii” Ron (Understanding “Kawaii”). Tokyo : Chikuma Shoten.

Harian Kompas. 2016. Apa itu Pokemon Go? http://tekno.kompas.com/read/2016/07/ 09/13200047/apa.itu.pokemon.go.

Horton, John. 2012. 'Got my shoes, got my Pokémon': Everyday geographies of children's popular culture. Centre for Children and Youth, The University of Northampton, Park Campus, Boughton Green Road, Northampton NN2 7AL, United Kingdom. 
Izumi, Volume 5, No 1, 2016

e-ISSN: 2502-3535, p-ISSN: 2338-249X

Tersedia online di http://ejournal.undip.ac.id/index.php/izumi

Loyde, Threeda. 2016. Demam Pokemon Go, Begini Asal Mula dan Tujuannya http://www.sumbernews.com/demampokemon-go-begini-asal-mula-dantujuannya/

Nobuyuki, Oku. 2007. Pelajaran Bahasa Jepang dengan BJ System Jilid 2. Jakarta: Kesaint Blanc

Nye, Joseph. S. Jr. 2004. Soft Power The Means to Success in World Politics. New York: Public Affairs.

Nye, Joseph. S. Jr. 2004. The Decline of America's Soft Power. Foreign Affairs. http://www.foreignaffairs.com/articles/ 59888/joseph-s-nye-jr/the-decline-ofamericas-soft-power

Nye, Joseph. S. Jr. 2008. Soft Power and Higher Education, Harvard University. http://net.educause.edu/ir/library/pdf/ff p0502s.pdf

Pudjomartono, Susanto. 2011 Soft diplomacy. http://www.suarakaryaonline.com/news.html?id=293039
Rininta, Chaula. (2015) Pop Culture: Revitalisasi Pengaruh Internasional Jepang. http://the-dailyjapan.com/pop-culturerevitalisasi-pengaruh-internasionaljepang/

Rollings, Andrew; Ernest Adams. 2006. Fundamentals of Game Design. Prentice Hall.

Diamond, Louise \& McDonald, John. Multi-track Diplomacy ; A System Approach to Peace. Kumarian Press.

Salen, K. and E.Zimmerman. 2003. Rules of Play : Game Design Fundamentals. MIT Press, Massachusetts.

Vuving, A. 2009. How Soft Power Works. Associate Professor, Asia-Pacific Center for Security Studies. Maluhia Road, Honolulu, HI 96815.

http://www.apcss.org/Publications/Vuving\% 20How\%20soft\%20power\%20works\% 20APSA\%202009.pdf 